УДК 332.14:352

\title{
Mathematical Modelling of Krasnoyarsk Transportation Web: Preliminary Results
}

\author{
Michael G. Sadovsky* \\ Institute of Computational Modelling SB RAS \\ Akademgorodok, 50/44, Krasnoyarsk, 660036 \\ Russia \\ Eugenia B. Bukharova ${ }^{\dagger}$ \\ Institute of Economics, Management and Environmental Studies \\ Siberian Federal University \\ Svobodny, 79, Krasnoyarsk, 660041 \\ Russia \\ Alexej V. Tokarev ${ }^{\ddagger}$ \\ Oleg E. Yakubailik ${ }^{\S}$ \\ Institute of Computational Modelling SB RAS \\ Akademgorodok, 50/44, Krasnoyarsk, 660036 \\ Russia
}

Received 24.11.2017, received in revised form 25.02.2018, accepted 02.04.2018

Graph-based model of Krasnoyarsk transportation web is proposed, with high resolution degree. Some preliminary results towards the properties of the web are considered. In particular, it is shown the traffic mapping has unimodal pattern and concentrates around Kommunalny bridge.

Keywords: graph, connectivity, power, bridges, separation.

DOI: 10.17516/1997-1397-2018-11-4-438-448.

\section{Introduction}

Studies on the modeling and management of urban road traffic are widely spread; the experience of China is of great importance here since the close similitude of the specific area of the road network (per resident capita) - SARN - and essential parallelism in economic and social history of the newest time.

SARN is the basic character determining the urban dynamics. This indicator is defined as the total area (not the length) of all roads, streets and lanes of a city, referred to the resident abundance. New York is the second to none: it shows $135 \mathrm{~m}^{2}$ per capita; Moscow is at the opposite end: $5 \mathrm{~m}^{2}$ per capita (according to 2010 records). There is no official data for Krasnoyarsk, but a good estimation yields the figure from 10 to $12 \mathrm{~m}^{2}$ per capita.

Being industrial city, Krasnoyarsk inheriting the road structure from the plans of Soviet era. It has almost rectangular pattern of roads and streets; many Chinese cities have the same

\footnotetext{
*msad@icm.krasn.ru

†ebuharova@sfu-kras.ru

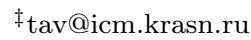

$\S$ oleg@icm.krasn.ru

(c) Siberian Federal University. All rights reserved
} 
structure. Finally, a certain similarity of social and economic history between Chinese cities and Krasnoyarsk is evident, e.g. the associated infrastructure of road network is rather poor.

\subsection{Basic approaches to model road traffic}

Probably, the problems number one of Krasnoyarsk is low road congestion that often causes a road jam. Qualitative and quantitative analysis of the costs (travel time, average speed, average speed variation, average standing time, etc.) makes the of great importance. The mechanism of road jam occurrence is analyzed in [1]. The traffic costs associated with jam are divided into four parts: additional travel time costs, environmental pollution costs, road accident costs and fuel costs. It is necessary to study in detail the quantitative indicators of these four external costs. It is shown the method to be quite feasible, serving a base for implementing pricing on the roads of country roads and other strategies for managing the demand for travel.

Another important source of transactions in functioning of a transport network of a city are the road accidents. Traditionally, accident statistics is used to assess the level of road safety and evaluate road safety programs. In some cases, the lack of good and reliable records of accidents complicates proper analysis. A promising approach that overcomes this problem is the technique of road conflict, which relies on monitoring critical traffic situations for security analysis and is described in [2]. It is necessary to study conflicts within a particular model.

Diurnal periodicity is A very important feature of any transport system of a city. In [3], the applicability and high efficiency of time series theory is shown. Such models can characterize different regimes of free flow, congestion and asymmetric behavior in the transition phases from free flow to congestion and vice versa. Models of smooth transients are presented with an emphasis on logistic multi-mode models, which are considered to be most suitable for traffic modeling. The methodology is illustrated by an appendix to data on rates of volumes and employment obtained from two data sources located at major road junctions in Athens, Greece.

Classical models of road traffic are based on hydrodynamic (called in [4] macroscopic fundamental diagram (MFD)). The models operate with average flows and average density, determined for sections of streets from the intersection to the intersection, even for the case when all or some of the intersections are synchronized (for example, by traffic light signals). Still such models are the most widespread and popular (see $[5,6]$. The feasibility and applicability of such models is proven in these papers.

Statistical features of flow behavior are also important for research and modeling. Traffic flows are examined using the urban highways [6]. Urban highway traffic differs from peripheral one, such as clusters on roads, more complex road conditions and lower speed limits. However, a comprehensive analysis of urban transport has not been carried out so far. In [6],the fundamental relations for urban highway characters are obtained.

A mixed-type model is considered in [7], where a new mixed-flow model is proposed to determine the basic statistical characteristics of traffic flows over transport networks of Beijing. The model consists of three parts. The main part is determined by the daily movements of residents, which remains relatively stable and resembles an $\mathrm{M}$-form curve, while random fluctuations follow some Gaussian distributions. The second part of the model describes "peaks" meeting a negative exponential distribution. Such model describe the behavior of time "peaks" in the traffic flow. These results enlighten the origin and characteristics of urban traffic to be used for forecasting and traffic control.

A new model of dynamic traffic model is proposed in [8] describing the process of a route selection. In this case, the model takes into account both topological structures and dynamic 
properties of traffic to solve problem numerically. Model describes the phase transition from free flow to a road-jam regime. Various topologies were examined where various local flows can facilitate an avoidance the road jam. Comparing to random networks, scale-free network models provide more active traffic. Finally, a dynamic traffic management model is proposed, maximizing the system throughput. Another simulation model of transport flows is presented in [9] using the data collected from cars equipped with special registration devices. Such cars play a role of test particles in flow models.

\subsection{Some special modelling approaches}

Urban traffic control systems heavily involve analogous CCTV data collection providing complex and scalable control system. Currently, digital video networks described in [10] allow to support an open urban traffic management system based on a commercial ready-made platform, as well as open source protocols and standardized protocols providing a solution with respect to scalability, cost, compatibility and performance for traffic management systems tasks. Additionally, the architecture can be easily adapted to other video applications and tools, such as control, surveillance or security systems for military and civil applications.

Another version of urban traffic management system is discussed in [11], where the algorithm for real-time management of urban traffic is considered. It was evaluated through comparison of two control strategies; the former is local one, and the latter is centralized one. Repeated traffic patterns, from peak traffic to low traffic, as well as the impact of adaptive flow capabilities, were studied. Some criteria of efficiency are new ones, since they are based on real-time data. Significant superiority of the algorithm is shown, especially in comparison to local strategies. Analysis of average behavior shows a higher average number of cycles per hour, greater duration of non-stop traffic per hour at the center of the intersection. These advantages are provided mainly by adaptive traffic control mechanisms.

Very important class of models of urban traffic dynamics is based on the application of neural networks. A typical example of this kind of model is the model described in the papers $[12,13]$. The papers discuss the problem of the gaps in data records. They make it difficult to model and manage a traffic system. Autoregressive shift average models (ARIMA) are used to fulfill gaps and predict missing values. Models based on the analysis of factors are usually less accurate. ARIMA models use only reliably obtained data. The mean errors for the refined models were below $1 \%$. Even in calculations with relatively low stability process characteristics, the average errors were mainly below $3 \%$.

The effective of models described above is impossible with no data provision. The methodology for on-line measuring of basic traffic parameters for intelligent transport systems (ITS) applications is discussed in [14]. This paper clearly illustrates an integration of theory and practice: the methodology includes a development of new model of dynamic traffic flow based on stochastic process of vehicles flux and the continuity of the flux. The model estimates the time of travel in a channel (street) and effect of real time data implementation on the flux estimations provided in real time. The results of modelling show that the estimates are in qualitative and quantitative agreement with empirical data collected at 2-minute intervals. The advantages of this model are its applicability in real time, high computational efficiency.

The model of traffic flows feasibility meets a number of technical problems; bulky data of large dimension is among them. For ITS discussed above, this problem is rather acute. An effective approach is proposed in [15], addressing an implementation of effective model of development of traffic jam. It is very important for ITS to provide them with real-time information with high 
accuracy to get a short-term traffic forecast. The paper implements a multidimensional spatial time series model using the data of the city network cell detector. Using 3-minute measurements of the volume of streams from city streets near the city center of Athens, the model yields the flow parameters of high concordance to observations. Also, very interesting and valuable approach in road traffic modeling is provided in [16].

\subsection{Side problems and effects: model solutions}

Transport flows are the main cause of atmospheric pollution in many cities worldwide. However, in addition to a conventional dust and combustion products pollution, cars produce acoustic pollutant. This problem is analyzed in [17]. The implementation and validation of the model to forecast the traffic dynamic based on combination of GIS, in association with the noise emission model taking into account the $2.5 \mathrm{D}$ propagation parameters on the basis of the directional pattern. This model takes into account the multiple reflections and diffraction. The model can be used to analyze the impact of real urban transport situations (for example, traffic flow control, road saturation) on noise level formation. The model also allows to calculate and visualize the statistical noise levels and the indicators obtained from them. The model of emission of solid particles from asphalt pavements is present in [18]. A simulation semi-empirical model based on a surveys carried out on busy streets in Central London is present. Finally, let's point out modeling of the social environment of a city [19]. In the article, the interaction of urban environment and types of transport flows with indicators of physical activity and public health is considered.

\section{Modelling of Krasnoyarsk transportation system}

The entire transport network of the city of Krasnoyarsk was represented as a graph; strictly speaking, the graph of any transport network is always oriented and, as a rule, any two vertices incident to an edge are connected by the second edge (of the opposite direction). This fact reflects most roads and their segments in the city of Krasnoyarsk have a two-way traffic. For simplicity, we showed such a graph as undirected one, where any undirected edge connecting two vertices means a two-way road (segment). The segments with one-way movement were explicitly indicated on the diagram as oriented edges of the graph.

The vertices of the graph are intersections or dead ends. The graph corresponds to January 1 , 2017 status of the traffic network. This graph is "almost planar": it means that the number of edges that must be removed in order to make the graph planar is very small; there are only seven such road junctions.

For a network presented by a planar (or "almost planar") graph, informative indicators comprise such topological characteristics as the vertex degree, that is the number of edges incident to a given vertex. The average vertex degree figure seems feasible for the city.

Tab. 1 presents this indicator for Krasnoyarsk entirely, and separately for right and left coast transport subsystems. In average, these two transport subsystems differ slightly. This difference brings an expectation of stronger differences for smaller fragments of the city. So, in general, road

Table 1. Specification of the road network nodes: 1 overall the city, 2 - left bank area, 3 - right bank area

\begin{tabular}{|l|r|r|r|}
\hline & \multicolumn{1}{|c|}{1} & \multicolumn{1}{c|}{2} & \multicolumn{1}{c|}{3} \\
\hline Average vertex degree & 2,699 & 2,704 & 2,692 \\
\hline Sum of vertices degree & 25722 & 14163 & 11332 \\
\hline Number of vertices & 9531 & 5237 & 4209 \\
\hline
\end{tabular}


network of the city has 12861 segments, among them 7078 segments are located on the left bank and 5662 segments are located on the right bank of the river. The sum of segments on the left and right banks does not coincide: 121 segments are located on the islands within the borders of Krasnoyarsk.

The study of topological characteristics of the road network of Krasnoyarsk in within the administrative regions gives more detailed picture. It should be said that the division onto administrative areas may completely not coincide with social stratification or with stratification determined by road network: that latter is a citywide "property" and its plan never follows the district level. Nevertheless, the district indicators of the topological characteristics of the road network are more informative than the average for the entire city.

Tab. 2 presents the indicators for the administrative districts of Krasnoyarsk. Surprisingly, there is a difference between two geographically and sociallydemographically similar regions: Zheleznodorozhny and Central. However, these differences are primarily determined by the difference in the areas of these areas; the Central district is more than three times larger Zheleznodorozhny one. Kirovsky district takes an intermediate position between

Table 2. Specification of the transportation system nodes: 1 - number of nodes in the system, 2 - average vortex power, 3 - number of segments (edges) in the graph, 4 - number of one way segments, 5 - area of the district, $\mathrm{km}^{2}$

\begin{tabular}{|l|r|r|r|r|r|}
\hline & 1 & 2 & 3 & 4 & 5 \\
\hline Zheleznodorozhny & 698 & 2,719 & 1013 & 145 & 11,9 \\
Central & 1304 & 2,727 & 1846 & 279 & 35,6 \\
Oktjabrsky & 1582 & 2,650 & 2145 & 109 & 90,2 \\
Sovietsjy & 1567 & 2,747 & 2233 & 397 & 89,4 \\
Leninsky & 1493 & 2,715 & 2071 & 237 & 49,8 \\
Kirovsky & 1208 & 2,705 & 1729 & 148 & 23,2 \\
Sverdlovsky & 1454 & 2,662 & 1987 & 138 & 77,2 \\
\hline
\end{tabular}

Zheleznodorozhny and Central, in terms of area. Tab. 3 contains these results. Fig. 1

Tab. 3 shows these indicators for administrative districts of Krasnoyarsk. The most interesting thing is the indicator present at the fifth column of Tab. 3. It means an average number of crossroads per inhabitant of the district; thus, Octyabrsky and the Sovietsky districts are "free" most of all. A reason for that may be a very large area, free from building or or extended industrial sites. The indicator in column 4 of the Tab. 3 is also transparent: this is an average number of crossroads (in relative units) per unit area of an administrative district. Zheleznodorozhny district is the absolute leader: maybe, because it is the smallest in size and very homogeneous in its spatial structure. For example, the Central and Soviet-

Table 3. Specification of the transportation system nodes: 1 - average population density, 2 - average vortex density, 3 - average edges density, 4 - average vortex power per $1 \mathrm{~km}^{2}, 5$ - specific (per capita) vortex power, $\times 10^{4}$

\begin{tabular}{|l|r|r|r|r|r|}
\hline & 1 & 2 & 3 & 4 & 5 \\
\hline Zheleznodorozhny & 7859,58 & 58,66 & 85,13 & 0,228 & 29 \\
\hline Central & 1546,63 & 36,63 & 51,85 & 0,077 & 50 \\
\hline Oktjabrsky & 1697,47 & 17,54 & 23,78 & 0,029 & 17 \\
\hline Sovietsjy & 3146,35 & 17,53 & 24,98 & 0,031 & 10 \\
\hline Leninsky & 2922,29 & 29,98 & 41,59 & 0,055 & 19 \\
\hline Kirovsky & 4944,61 & 52,07 & 74,53 & 0,117 & 24 \\
\hline Sverdlovsky & 1691,66 & 18,83 & 25,74 & 0,034 & 20 \\
\hline
\end{tabular}
sky districts show very strong heterogeneity (see Figs. 2-4).

In order to reveal the feature of various fragments of the urban area, all the indicators listed above were computed to for a square grid of $12 \times 15$ cells, with each cell size as big, as $2 \times 2 \mathrm{~km}^{2}$. Fig. 2 illustrates these calculations: three clusters are clearly distinguished in the historical part 
of the city (Central and Zhelyznodorozhny districts, in the area of the Metallurgov prospect and in some part of Kirovsky district.

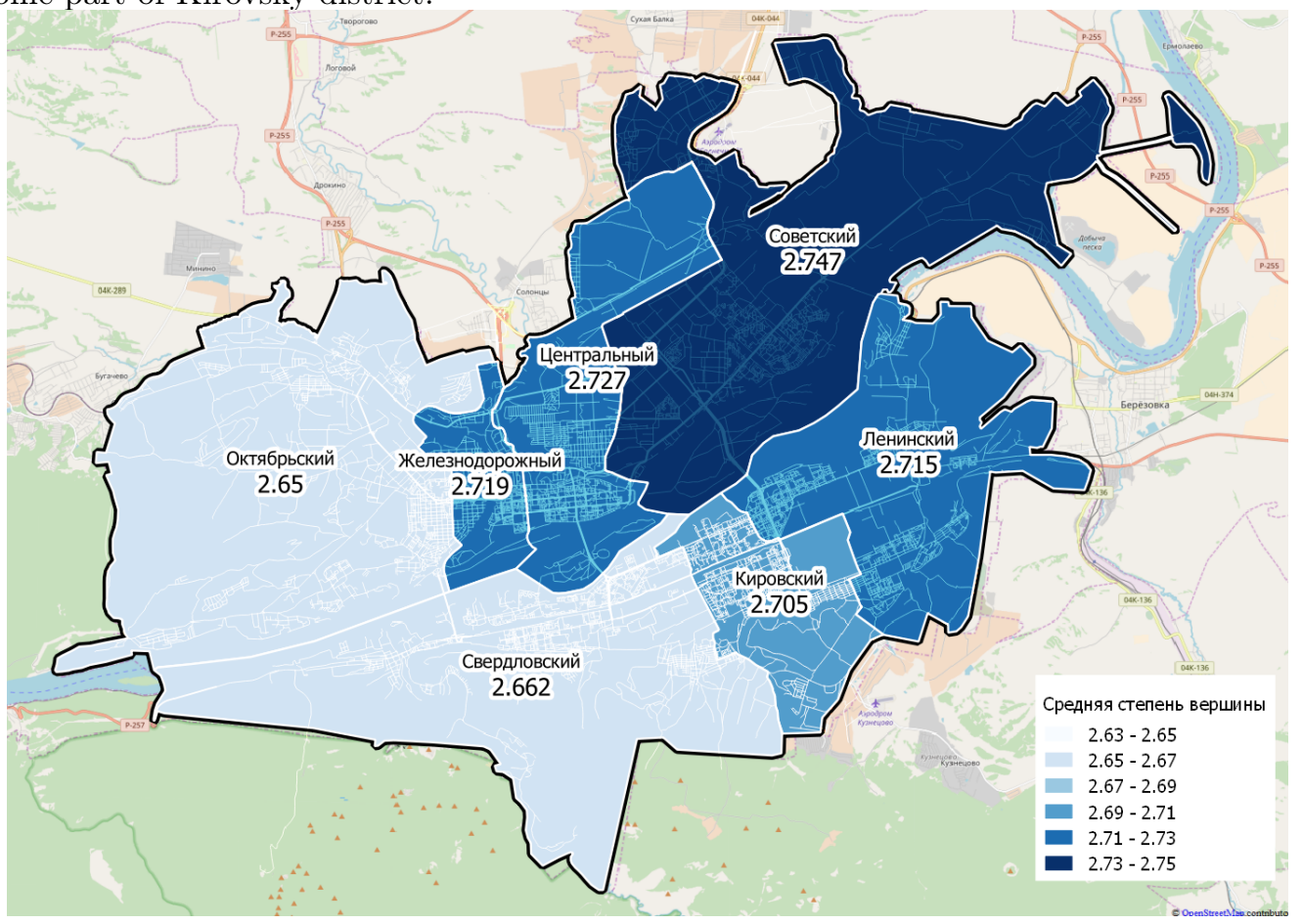

Fig. 1. Distribution of average vortex degree over the districts of Krasnoyarsk

The transport network of Krasnoyarsk is rather inhomogeneous and the distribution of the average degrees of the vertices of graphs is very heterogeneous; we recall that this indicator represents a specific number of crossroads that occur on a given section of the urban territory. Here the clusters are much larger and they are completely different. A large number of clusters (see Fig. 3) on the periphery of the city can be explained, apparently, by the detailness of the city map used in the study: many small roads (and quite a number of them have no asphalt cover) and lanes, located around of industrial zones of the city. The distribution of the number of segments (fragments of streets and roads stretching from one intersection to the other) through the city is significantly more informative from this point of view; this distribution is shown in Fig. 4 showing the distribution densities of segments and the distribution density of segments with one-way traffic.

\section{Modelling of traffic with random simulation}

Analysis of the transport network in Krasnoyarsk should not be limited to the topological properties of the graph of city road network. It is very important to analyze the density of possible routes of vehicle around the city. To do that, we have carried out the following computational experiment: on the city map, 10000 points were randomly and uniformly selected. Then 10000 pairs were randomly selected in this set of points; for each of the points in the selected pair, the nearest graph node (intersection or deadlock) was determined and then 10000 shortest routes between these points have been constructed. The length of each route was defined topologically, as the smallest number of edges (road segments) comprising the route running from one point 


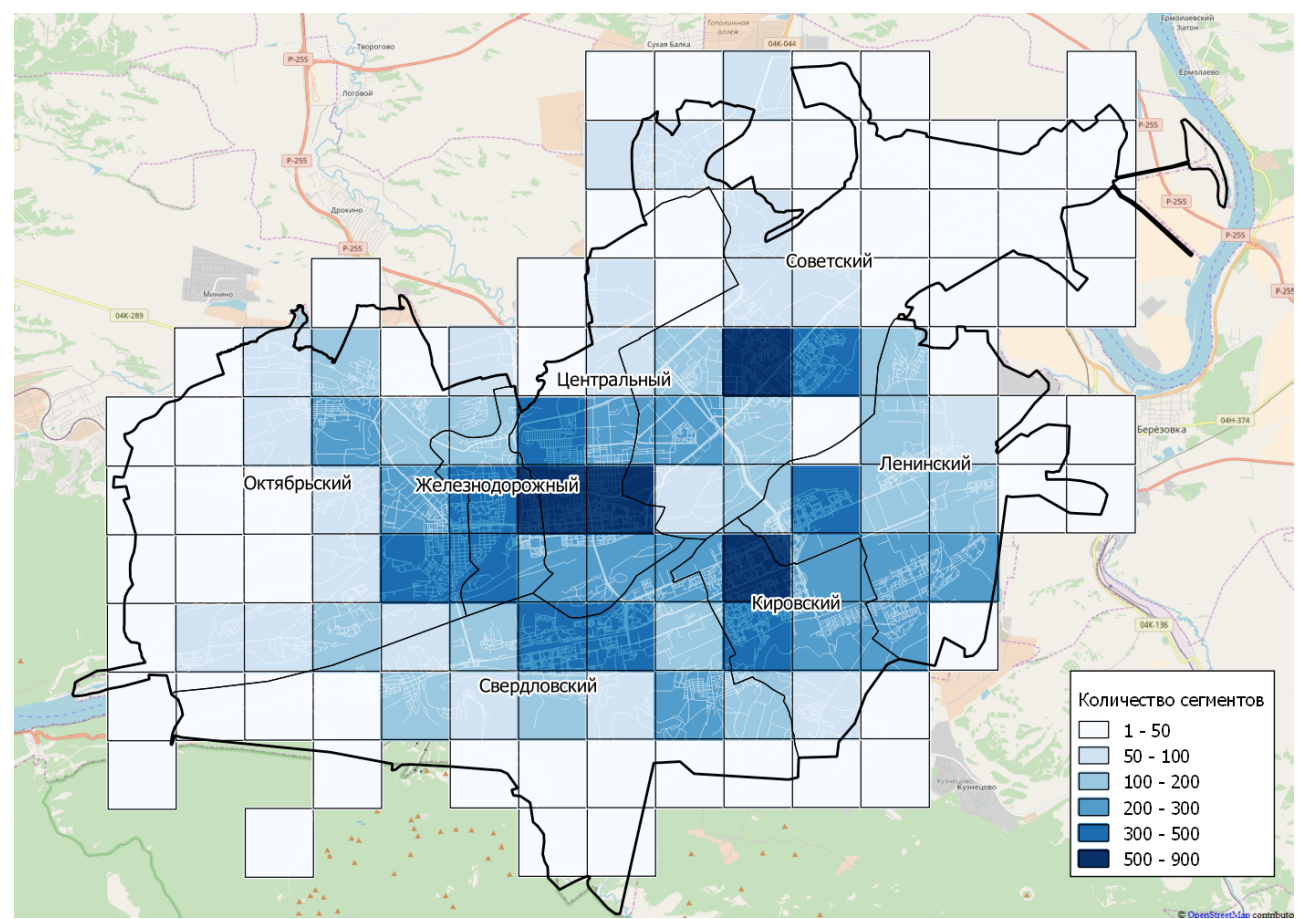

Fig. 2. Distribution of the number of vertices of transportation system of Krasnoyarsk over the square web of $2 \times 2 \mathrm{~km}$ size

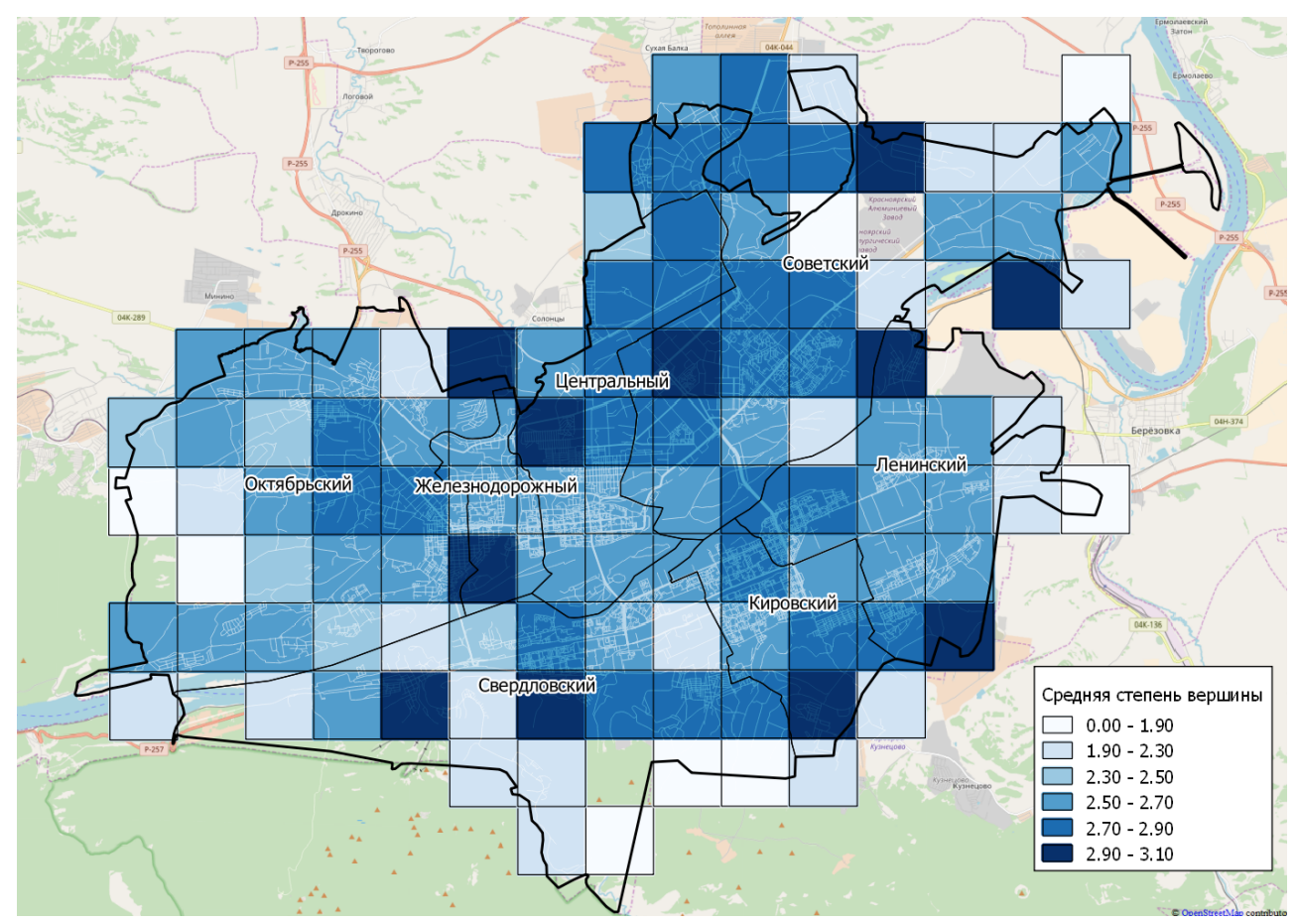

Fig. 3. Distribution of the average power of vertices of transportation system of Krasnoyarsk over the square web of $2 \times 2 \mathrm{~km}$ size 

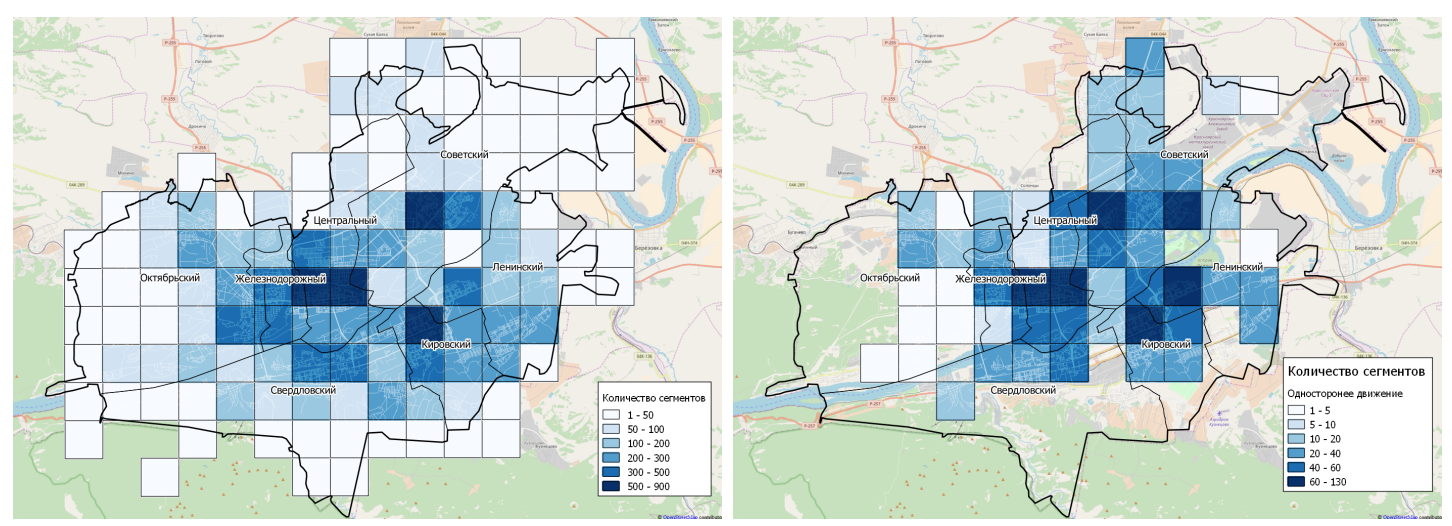

Fig. 4. Distribution of the number of segments of transportation system of Krasnoyarsk (left) and those for one-way segments over the square web of $2 \times 2 \mathrm{~km}$ size

(starting) to the second (finish). Fig. 5 illustrates this process (it shows only five random routes out of 10000 , as an illustration).

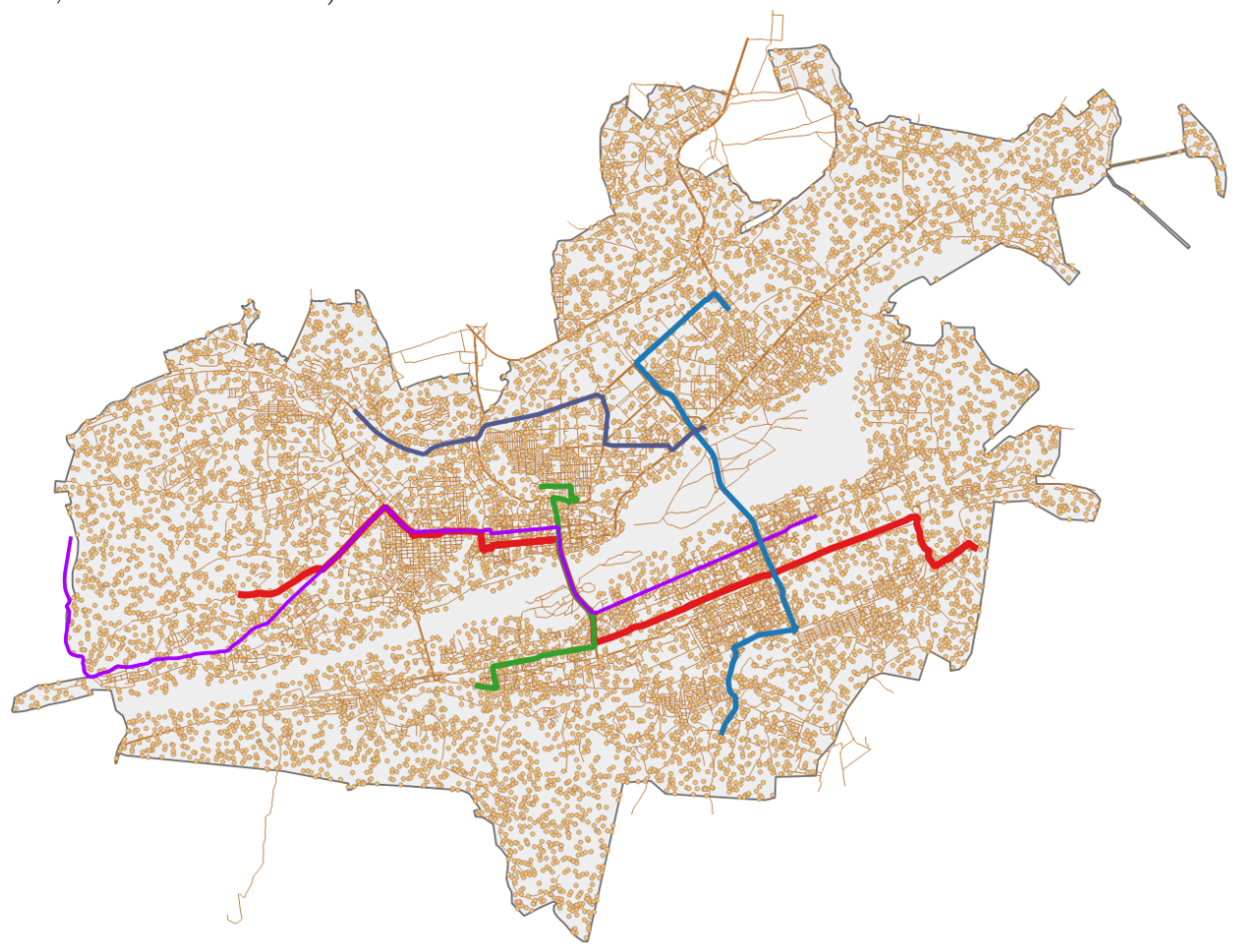

Fig. 5. Random routs - example

The main goal of this experiment was to identify those edges of the graph that have an unusually increased frequency of occurrence in the ensemble of random routes. The idea of the experiment is that such random routes simulate with good accuracy the real daily movement of vehicles along the street-road network in Krasnoyarsk. Another point is that we determine those segments of the road network, that have the greatest load, assuming that drivers of vehicles choose routes close to the shortest one. This assumption seems rather feasible. 
Fig. 6 presents a map of the frequency of usage of different segments of the road network, for the shortest routes between two randomly chosen points to be constructed. It should be stressed that the data on the frequency of segment usage were on 5000 long routes, but not on all 10000 random routes; all shorter routes have been excluded from consideration.

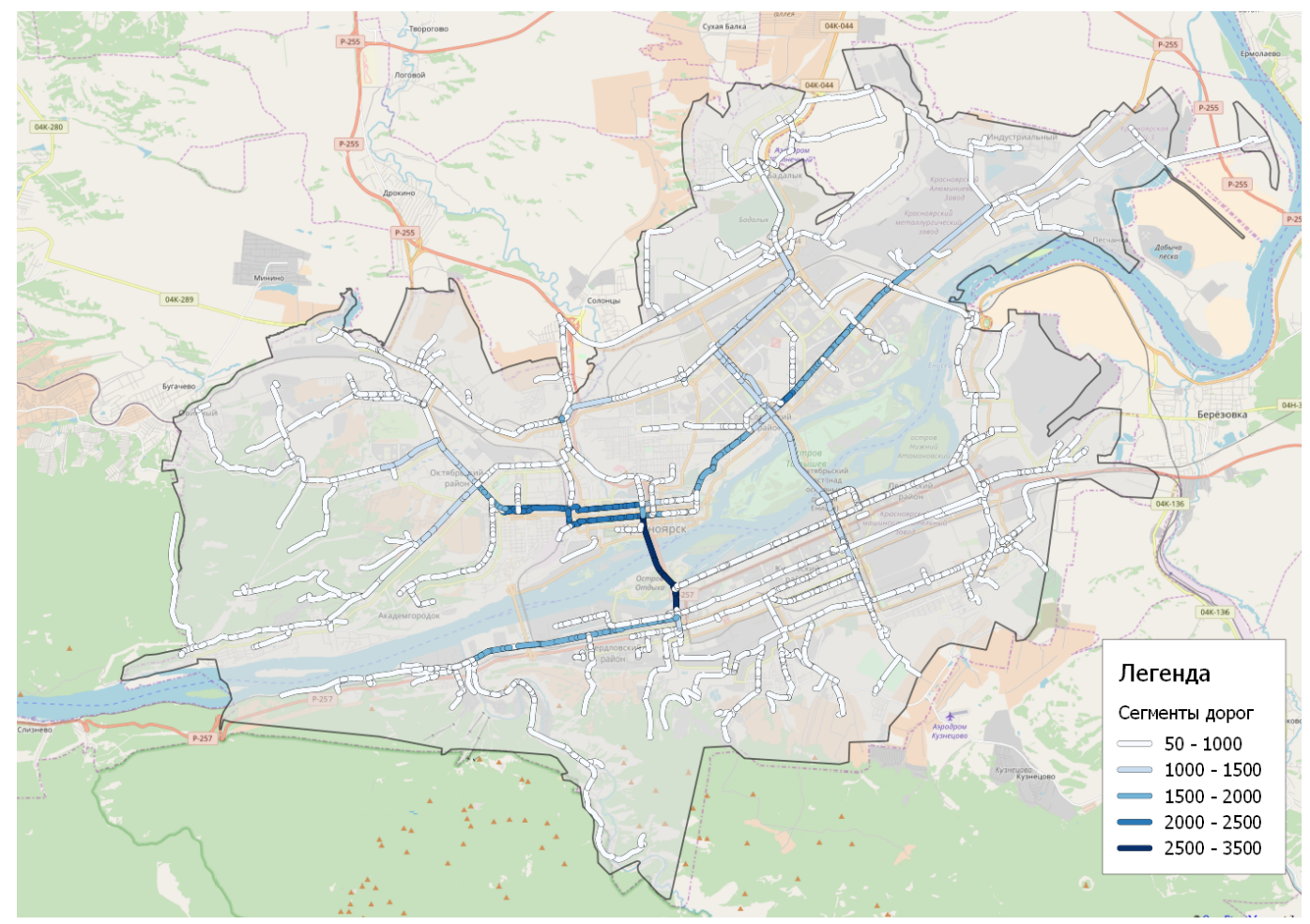

Fig. 6. Frequency distribution of the segments usage, for shortest possible routs

\section{Conclusion}

The road network of Krasnoyarsk is an "almost planar" graph with rather lower connectivity: there are a set of segments (edges in the graph) in the city, which exception break the connected transport network of the city into separate disconnected subgraphs. These segments are all the bridges across the river Enisey, located within the city, as well as streets Kalinina, Kopylova and Svobodny Prospekt. Other critical points are the streets of Michurin, Matrosov and the current ramp-off from the $4^{\text {th }}$ bridge, which exclusion from the UDS graph results in a loss of connectivity with part of the city's transport system, divided into two incoherent subgraphs by the railroad.

The road network of the city is very uneven in different parts of the city, according to the average degree of a vortex of the graph. Identification of the most frequent road network segments comprising long-distance routes also reveals a low level of connectivity and illustrates the origin of traffic jams. These results are rather preliminary; it is necessary to take into account the characteristic values of traffic flows along different streets in Krasnoyarsk (go to the analysis of the weighted graph of the road network), redefining the shortest paths using the edge weights. Further, a model with various strategies for transport flows control should be studied in order 
to determine the optimal scenarios.

The study is carried out under the grant «Mетодические подходы $\kappa$ формированию концепции создания проекта "Умный город (SmartCity)" в контексте трендов развития иифровой экономики» from Krasnoyarsk Regional Science \& Technology Foundation.

\section{References}

[1] Luo Qingyu, Juan Zhicai, Sun Baofeng, Jia Hongfei, Method Research on Measuring the External Costs of Urban Traffic Congestion, J. Transpn. Sys. Eng. \& IT, 7(2007), no. 5, 9-12.

[2] H.-C.Chin, S.-T.Quek, Measurement of traffic conflicts, Safety Science, 26(1997), no. 3, $169-185$.

[3] Y.Kamarianakis, H.O.Gao, Poulicos Prastacos, Characterizing regimes in daily cycles of urban traffic using smooth-transition regressions, Transportation Research C, 18(2010), $821-840$.

[4] C.F.Daganzo, N.Geroliminis, An analytical approximation for the macroscopic fundamental diagram of urban traffic, Transportation Research B 42(2008), 771-781.

[5] H.Xiaowen, Y.Dongyuan, Estimation of Traffic Density on Urban Freeways, J. Transpn. Sys. Eng. \& IT, , 8(2008), no. 3, 79-82.

[6] W.Guan, S.He, Statistical features of traffic flow on urban freeways, Physica A, 387(2008), 944-954.

[7] L.Zhiheng, Y.Shengchao, T.Ye, L.Li, Z.Zhiqiang, J.Yan, Urban Traffic Flow Volume Modeling for Beijing Using a Mixed-Flow Model, J. Transpn. Sys. Eng. \& IT, 8(2008), no. 3, $111-114$.

[8] J.J.Wu, H.J.Sun, Z.Y.Gao Dynamic urban traffic flow behavior on scale-free networks, Physica $A, \mathbf{3 8 7}(2008), 653-660$.

[9] Z.Wei, X.Jianmin, W.Haifeng, Urban Traffic Situation Calculation Methods Based on Probe Vehicle Data, J. Transpn. Sys. Eng. \& IT, 7(2007), no. 1, 43-49.

[10] M.Esteve, C.E.Palau, J.Martínez-Nohales, B.Molina, A video streaming application for urban traffic management, J. of Network and Computer Applications, 30(2007), 479-498.

[11] F.Boillot, S.Midenet, J.-C.Pierrelée The real-time urban traffic control system CRONOS: Algorithm and experiments, Transportation Research $\boldsymbol{C}$, 14(2006), 18-38.

[12] S.Feng, H.Enhou, C.Qun, W.Yingzi, Optimization of One-Way Traffic Organization for Urban Microcirculation Transportation Network, J. Transpn. Sys. Eng. \& IT, 9(2009), no. $4,30-35$.

[13] M.Zhong, P.Lingras, Satish Sharma Estimation of missing traffic counts using factor, genetic, neural, and regression techniques, Transportation Research C, 12(2004), 139-166.

[14] Do H.Nama, D.R.Drew, Automatic measurement of traffic variables for intelligent transportation systems applications, Transportation Research B, 33(1999), 437-457. 
[15] A. Stathopoulos, M.G. Karlaftis, A multivariate state space approach for urban traffic flow modeling and prediction, Transportation Research C, 11(2003), 121-135.

[16] C.Hofer, G.Jäger, M.Füllsack, Generating Realistic Road Usage Information and OriginDestination Data for Traffic Simulations: Augmenting Agent-Based Models with Network Techniques, In: Cherifi C., Cherifi H., Karsai M., Musolesi M. (eds), Complex Networks \& Their Applications VI. COMPLEX NETWORKS 2017, Studies in Computational Intelligence, vol. 689, 2018, 1223-1233.

[17] B.De Coensel, T.De Muer, I.Yperman, D.Botteldooren, The influence of traffic flow dynamics on urban soundscapes, Applied Acoustics, 66(2005), 175-194.

[18] A.Patra, R.Colvile, S.Arnold, E.Bowen, D.Shallcross, D.Martin, C.Price, J.Tate, H.ApSimon, A.Robins, On street observations of particulate matter movement and dispersion due to traffic on an urban road, Atmospheric Environment, 42(2008), 3911-3926.

[19] H.Badland, G.Schofield, Transport, urban design, and physical activity: an evidence-based update, Transportation Research D,10(2005), 177-196.

\title{
Математическое моделирование красноярской транспортной сети: предварительные результаты
}

\author{
Михаил Г. Садовский \\ Институт вычислительного моделирования СО РАН \\ Академгородок, 50/44, Красноярск, 660036 \\ Россия \\ Евгения Б. Бухарова \\ Институт экономики, управления и природопользования \\ Сибирский федеральный университет \\ Свободный, 79, Красноярск, 660041 \\ Россия \\ Алексей В. Токарев \\ Олег Э. Якубайлик \\ Институт вычислительного моделирования СО РАН \\ Академгородок, 50/44, Красноярск, 660036 \\ Россия
}

Рассмотрена модель транспортной сети Красноярска на основе графового представления, имеющая высокую степень разрешения. Представлены и проанализированы некоторые свойства этой сети. В частности, показано, что городской трафик имеет унимодалъное (по плотности) распределение с иентром вокруг Коммунального моста.

Ключевые слова: графы, связность, степень вершины, мосты, разделимость. 